\title{
'Just shut up and let them talk': Participation, power and the parent voice in the child protection system
}

\author{
Marie Gibbons ${ }^{1}$ and Nuala Connolly ${ }^{2}$
}

\begin{abstract}
Participatory practice is acknowledged as increasingly important in empowering families in the decision-making process. Yet parental participation in child protection and welfare settings remains a complex and multi-dimensional practice, dependent on a range of individual factors including willingness to engage; understanding of need, as well as system factors including power dynamics and resource constraints (Darlington et al., 2010). Parents can feel 'powerless and helpless' when not involved in decision-making processes (Hardy \& Darlington, 2008). In addition to practice wisdom emerging from literature in the field, this paper examines the findings of a research study commissioned by Tusla (the Irish, national, statutory Child and Family Agency) on parental experiences of Child Protection Conferences (CPCs) in Counties Galway and Roscommon. Analysis of findings of a series of qualitative interviews $(n=14)$ with parents who have attended CPCs, found that parents in the study felt unprepared for CPC, unclear of the implications for their families and felt marginalised by the CPC process. While many parents recognised their right to reply, most reported wanting to appear cooperative. The paper proposes recommendations including the development of a protocol for CPC preparation; participation supports for parents to ensure their voices are heard throughout the process; debriefing as a structured phase of the CPC; and continuous intensive engagement with parents post-CPC.
\end{abstract}

Keywords: parents; participation; child welfare; child protection; Child Protection Conference; CPC; voice; silence; decision-making; power

1. Researcher, Tusla / Galway and Roscommon Children and Young Person's Service Committee (at time of writing)

2. UNESCO Child and Family Research Centre, School of Political Science and Sociology, National University of Ireland, Galway (at time of writing)

Address for correspondence: marie.gibbons@tusla.ie

Date of first (online) publication: 30th September 2020 


\section{Introduction}

Participatory practice is acknowledged as increasingly important in empowering families in the child protection decision-making process. Parental participation represents a shift from viewing parents as passive beneficiaries to an emphasis on the capacity of service-users to be creative, reflective and active agents in shaping their lives (Slettebo, 2013). Despite this shift, parental participation in child protection and welfare settings remains a complex and multi-dimensional concept, with limited research with parents available. Participation by parents in the child protection context is also dependent on a range of individual factors including willingness to engage, understanding of needs, and willingness to effect changes in order to meet those needs, as well as system factors including power dynamics and resource constraints (Darlington et al., 2010). This paper draws on new and existing research to explore what parents want across the continuum of participation and how this might be realised and embedded in child protection services. This article has a particular focus on the context of emerging structures for parental participation within Ireland's new Child and Family Agency, Tusla. The paper will explore practice wisdom emerging from research and literature in the field. In addition, primary data from a report on parental experiences of Child Protection Conferences (CPCs) in a selection of western counties in the Republic of Ireland will be explored. A CPC is convened by a Conference Chairperson when a Tusla social worker, in consultation with a Team Leader, determines that there are grounds for believing that a child is at ongoing risk of significant harm from abuse or neglect. The purpose is to determine whether a child is at ongoing risk of significant harm; to facilitate the sharing of information in order to identify risk factors, protective factors and the child's needs; and to develop a child protection plan when it has been determined that a child is at ongoing risk of significant harm. This paper will include the findings of 14 qualitative interviews with parents who have attended CPCs, exploring their experiences of the process, the supports they received and the impact on their family lives. The paper provides recommendations for practice borne out by research and illustrates the importance of engaging with parents in contributing to improved outcomes for children and families.

\section{The policy context}

An increasing emphasis on participatory practice and consultation with service users is evident in family policy in both the UK and Ireland. The origins of participation as a policy imperative in child protection settings can be traced back to the 1980s. Section 22 of the UK's Children Act 1989 places a duty on local authorities to consult parents before making any decision with respect to 
a child in their care. In Ireland during the 1990s, the Law Reform Commission also advocated for parents to be given the opportunity to comment on any action proposed by the Child Protection Conference (Law Reform Commission, 1990). The landmark report of the Kilkenny Incest Investigation found that all reasonable steps should be taken to facilitate the attendance of relevant persons at CPCs, and that the attendance of parents or guardians would be the norm 'unless there are substantial grounds for their exclusion' (Department of Health, 1993). There is no equivalent provision contained in the Child Care Act, 1991 (Kilkelly, 2004), and no aspirations towards parental involvement had been formalised in Ireland during the first half of the 1990s, with 'parental attendance at meetings rare and children's participation in placement reviews almost non-existent' (Department of Health and Children, 2008b, p.18).

Despite this, the guidelines for 'Notification of Cases of Suspected Child Abuse between the Health Boards and Gardaí' (Department of Health, 1995) reported that the practice had developed in some Health Board areas of inviting the parent(s) of the child to participate at the CPC (Department of Health, 1995, p.14). The practice of inviting parents to CPCs was formalized in 1999 by the implementation of the Child First National Guidance for the Protection and Welfare of Children (Department of Children and Youth Affairs, 2011). The policy states that "parents/ carers have a right to respect and should be consulted and involved in matters that concern their family' (Department of Children and Youth Affairs, 2011, p. 4), while also providing that 'the views of parents/ carers should be sought on the issues to be raised at a CPC, so that they can get advice and prepare their representations' (Department of Children and Youth Affairs, 2011, p.50). The current definition of the Child Protection Conference references interagency working and parental involvement. The CPC is defined as 'an interagency and inter-professional meeting, convened by the designated person in the HSE' [now Tusla], the purpose of which is 'to share and evaluate information between professionals and parents, to determine if there is an ongoing risk of significant harm to the child and consequently to formulate a child protection plan' (Child and Family Agency, 2015, p.5). CPC guidance states that 'the participation of all those invited to a CPC is expected and essential to its success' (Child and Family Agency, 2015, p.10).

The Children Act 2001 (Pt 2) (Department of Children and Youth Affairs, 2001) makes provision for family welfare conferences (FWC) in child welfare and youth justice cases, the purpose of which is to resolve a care and protection issue before the courts or as a preventative strategy with a child (Brady, 2006). This alternative model takes a different approach to the CPC in that it "promotes the principle of family-based decision-making and has its roots in the strengths-perspective models of intervention' (Department of Health and Children, 2008, p. 19). The model is seen as more empowering than traditional ways of working (Lupton, 1998). It is defined in an Irish context as a 'family-led process which offers families the opportunity to make a safe family plan to address their needs in the best interests of 
the future safety and welfare of their children' (Child and Family Agency, 2011, p.7).

Participatory practice and consultation with service-users and parents has continued to gain momentum as a policy imperative in recent years. The HighLevel Policy Statement on Parenting Support (DCYA, 2015) emphasizes 'partnership with children and their parents'. The purpose of the Statement is to strengthen parenting and family support, while also providing a policy imperative to build on the evidence-base for parenting support and to 'ensure that parents and children are key participants in that process' (ibid, p. 2). The Statement is designed to support the work of Tusla (the Child and Family Agency) as set out under the Child and Family Agency Act 2013. Tusla has recognised the need to embed the participation of children and parents in its culture and operations among the organization's medium term outcomes. Notable in Tusla's programme of work in prevention, partnership and family support (PPFS) is the Parenting Support Strategy, focusing on prevention and early intervention approaches that help children, young people and their families realise their true potential (Gillen 2013, p. 7). Partnership working and participation are key implementation principles of the Strategy, with a Toolkit for Parental Participation developed to support this work (Child and Family Agency, 2016).

In addition, Tusla has developed Meitheal, a National Practice Model, as an early intervention, multi-agency (when needed) response tailored to the needs of the individual or young person. The approach has been developed to support families with additional needs who may require multi-agency support but who do not meet the threshold for referral to social work. The term Meitheal is an old Irish term describing how neighbours and communities work together in cooperation and reciprocal support. In this context, the process is voluntary and requires parental consent. In addition, convening the meeting is dependent on the involvement of at least one parent. The participatory approach of the Meitheal process privileges the voices of the parent or carer and child, recognising them as experts in their own situations and assisting them to identify their own needs and ways of meeting them (Child and Family Agency, 2015).

\section{Parental participation and the parent voice}

Participation has been defined in the literature as 'the involvement of service-users in the planning, delivering and evaluation of parenting support', with partnership defined in broader terms as working in partnership with all stakeholders, particularly parents, in relation to the development, delivery and monitoring and evaluation of parenting support services (Gillen et al., 2013, p.16). This trend for participatory practice is based on an increasing desire to enable users to exert influence on the services they receive (Slettebø, 2013), considered both ethical 
and effective (Corby et al., 1996, p.476). As such, participatory practice has been defined in terms of a wider trend towards more openness and accountability on the part of the public services and a shift from seeing people as passive beneficiaries of welfare to 'emphasise the capacity of service users to be creative and reflexive and active agents in shaping their lives and acting upon the outcomes of welfare policies' (Slettebø, 2013, pp.578-580). Parents can be involved in services at a number of levels including decision-making within service delivery, involvement in case planning and involvement in service evaluation, monitoring service planning, and strategic planning (Katz et al., 2007). The nature and level of this involvement has been conceptualized in a range of ways.

Arnstein's ladder of citizen participation, includes the levels of informing, consultation and placation, all of which Artstein refers to as tokenistic (Arnstein, 1969, p.217). Preferable is the level of partnership, situated above consultation, which can enable citizens to negotiate and engage in trade-offs with traditional power holders. Lundy's (2007) model of children's participation provides a way of conceptualizing Article 12 of the United Nation's Convention on the Rights of the Child (UNCRC) (United Nations, 1989). Lundy's perspective is less hierarchical, with the approach focusing on four interrelated elements of space, voice, audience and influence. While Lundy's is a model of children's participation, it has been positioned as postmodern in its approach, facilitating the sustainability of empowerment beyond the interaction itself (Mannion, 2009).

Roose et al. (2013) develop beyond thinking solely in terms of levels of participation and methods of partnership to focusing on how engagement can be constructed with families. As a contrasting example, they identify non-participation as an essential element of partnership, rather than as problematic or irrelevant. From a reductionist perspective, undesirable behaviour among service users can be seen as problematic, reducing partnership to a protectionist approach. The outcome is that professionals may then activate parents to realise goals set by social work. Roose et al. (2013) argue that a system of democratic, shared responsibility would ensure non-participatory acts are also deemed as meaningful to the overall process. Participatory practice may occur at various levels of involvement of the service user in the service and decision-making process, but in some contexts participation itself may be the goal, and thus non-participation remains an element of partnership, with non-participatory acts deemed as meaningful.

Participatory practice is also complicated by power relations. In child protection contexts, the concerns of professionals and parents are not always mutual, especially where the quality of parental care may be in question (Corby et al., 1996, p.485). The process is complicated in a child protection context: 'Parents are often the subjects of investigation as well as clients in need of assistance with the challenges they face in protecting their children and promoting their wellbeing' (Healy et al., 2012, p.10). Despite this, the relationship between parents and providers is a major factor influencing the engagement of parents in mainstream services (Corby et al., 
1996). Parents may feel that the CPC does not allow them to initiate discussion about their concerns (Corby et al.,1996). Working in partnership is dependent on parents being treated with respect, feeling they have a voice and experiencing good communication and flexibility on the part of services (Darlington et al., 2012; Healy et al., 2011). This is most likely when opinions are sought. Research demonstrates that simple measures including personal introductions, straightforward language and eye contact can impact positively on parental participation (Ayón et al., 2010). It has been found that where parents found their views to be dismissed by social workers, their overall experience was less positive (Höjer, 2011).

Exploring further prohibitive factors to participation, it is noteworthy that parents can feel powerless and helpless when not involved in decision-making processes (Hardy and Darlington, 2008). Similarly, where the language used is unfamiliar or where parents are in the presence of a number of professionals and feel outnumbered, the experience can be less positive (Farmer and Owen, 1995). This is especially challenging in the child protection context, where factors inherent to the process can act as a constraint to parental participation. Involvement of parents in the child protection system is not typically a voluntary experience and the inherent tensions that exist create a type of power asymmetry that may leave parents feeling threatened. They may also feel that decisions have already been reached and that negotiation will not occur (Darlington et al., 2010). They may prefer to disclose less, concerned that information may be used against them (Ayón et al., 2010). In such scenarios, parents may go so far as to exercise their voice with a view to appearing cooperative (Sletteb $\varnothing, 2013$ ). It has been noted that professionals play an essential role in supporting parents in this regard, and as such require 'relational and communicative competence' (Aarthun and Akerjordet, 2014, p. 188). It is also important to acknowledge the varied needs of different groups of parents at different times. Katz et al. (2007) identify parents from minority communities, parents with disabilities, fathers, and parents living in poverty as facing barriers to participation. Barriers can be physical, including access and geographic location, as well as social barriers, including cultural institutions and structures that impinge on individuals, such as gender and ethnicity (Katz et al., 2007).

A small body of existing research identifies the protective and prohibitive factors to successful parental participation in child protection. It has been noted that given the importance of the role of social workers in this process, this topic is especially under researched with relatively few small-scale studies undertaken in the last 30 years (Horwath and Tarr, 2014). This paper also draws on practice wisdom emerging from research undertaken in the Irish context in 2016, which is now described.

Parents in the Child Protection Conference (CPC) system in the West of Ireland.

Based on an identified need for quality data in the Irish context, a study of parents' experiences of the CPC was commissioned by Tusla in 2016. The objectives of the study were to explore parental understandings of the reasons why their children were the subject of a $\mathrm{CPC}$; to consider the support and preparation they 
received prior to, during and after the $\mathrm{CPC}$; to uncover parental experiences of attending a $\mathrm{CPC}$ including the extent to which parents felt listened to, and had their views respected during the conference; to evaluate perceptions of parents on the impact on their family lives of attending a CPC and the effectiveness of the Child Protection Plans (CPP) developed in the CPC; and to make recommendations for chairpersons and social workers in Tusla who are involved in CPCs. The data was collected through one-to-one semi-structured qualitative interviews and was analysed using thematic analysis.

\section{Recruiting seldom-heard participants}

As evidenced above, parents whose children are in the child protection system are a population with significant identified vulnerabilities and whose data and confidentiality must be robustly respected by Tusla. They are also parents who may perceive there is a shame or stigma due to their children requiring a child protection intervention, and who are often unfamiliar with child protection processes, mechanisms and settings. These factors may explain why this group of parents are typically a hard to reach population and consequently under researched. With this in mind, the Independent Chair of the CPC system acted as a gatekeeper for the project and as a result seventy-five parents who had been in the CPC system in a selection of West of Ireland counties were identified and contacted by letter from the gatekeeper and invited to take part in the study. Follow up phone calls were made by the gatekeeper to all parents to explain the research in more detail and fourteen parents agreed to participate in the study and consented for their contact details to be provided to the researcher. Given the sensitive nature of the study and the possibility that parents may feel pressure to take part, the phone call from the Gatekeeper sought to reassure parents that their decision to take part or not would be fully respected and no explanation was needed if they were not interested in participating.

Parents were advised by the researcher that their participation in the study would be conducted in the strictest confidence and would have no impact on any other interactions they might have with Tusla. The researcher informed parents of her status as a Tusla employee, but with no involvement in the CPC system and this information was shared with parents early in the recruitment process. The parents were subsequently asked to sign a form indicating that they agreed to have contact with the researcher and that they had provided their contact details willingly. These measures were designed to ensure that this study complied with research ethics and data protection requirements.

The 14 parents who participated in this study were living in the designated catchment area for the study during the period of data collection. Not all of the 
parents were originally from these areas and some had moved from other counties in Ireland. Two parents were from outside Ireland. Six of the participants were fathers and eight were mothers. Four couples participated in the study, of which three were married. Two of the participants were from the Travelling Community. All parents had attended at least one initial CPC and one review meeting, with the number of CPCs or review meetings attended by parents varying from two to eight. Review meetings are convened within a timeframe which has been agreed at the CPC, and its purpose is to review the Child Protection Plan agreed at the CPC. Three parents reported that the initial CPC was called shortly after their first contacts with the social work department, on an emergency basis. Four parents reported multiple conferences going back to 2009; however, the majority of parents attended an initial CPC in 2014, with a review meeting held in either 2014 or 2015. None of the children of any of the parents interviewed were listed as active cases on Tusla's Child Protections Notification System at the time the research interviews were conducted. However, five parents reported that at the time of the research interview they were still receiving varying levels of social work or family support interventions from Tusla, in relation to other children at home, or in a small number of cases, in care.

\section{Key findings and discussion}

The findings and analysis are presented in a chronological format that traces parents' experiences of the process, including how they were prepared for the initial CPC, their emotions and reactions before and during the CPC, their experiences in the time period between the initial CPC and the review meeting. It also reflects parents' recommendations for the roles of CPC chairpersons, social workers and other parents who are going through a similar process.

\section{Prior to the Child Protection Conference}

The majority of parents in the study reported not having all the information they needed on the purpose and conduct of the CPC and most parents reported not having access to written copies of any professional reports in advance of the meeting. The lack of information on how the CPC would be run, who would participate and what parents could expect is reflected in other studies such as Guinan (2004) who found that professionals did not fully explain to parents the nature and purpose of a CPC beforehand. This resulted in parents not having a good understanding of the process nor of what they could expect during and after the CPC, and what was expected of them in terms of their participation. Two parents recalled that they 
were not fully informed that the meeting was to be a Child Protection Conference beforehand:

... it wasn't mentioned at all that this was a child protection conference, it was just a 'meeting'. They were calling it a meeting. It sort of dawned on me during the meeting what it was.

Parents reported differing accounts of their knowledge and understanding of the reasoning underpinning the decision to convene a CPC. Some parents were clear and had been well informed:

She said it was because of the neglect of the children, the neglect and the violence at home that has really impacted on the children.

Others were less sure of the reasoning behind the decision to convene the CPC, 'we had no clear idea really, why it was going ahead'. This lack of clarity as to the reasoning behind the decision to convene a CPC is common to many of the testimonies of the parents in the study. It would appear that without prior, adequate information on the reasoning behind the decision to call a CPC, parents are trying to put the pieces together during the CPC, and this can act as a barrier to engagement and participation, particularly with respect to voice and influence (Lundy, 2007).

For the most part, parents in this study reported that they were not clear on the range of the possible implications of the CPC. All parents in this study were fearful that their children would be removed from their care as a direct result of the CPC: 'What I thought about it was that the kids would be taken off us... that was my biggest fear'. Largely as a result of this fear, and compounded by the lack of preparation, parents reported experiencing a range of distressing emotional responses including panic and fear: 'I was freaking out and I was having panic attacks a few days before the meeting'. Very few parents in this study brought a support person or advocate with them to the CPC. There appears to have been little in the way of discussion with social workers on this point prior to the CPC, and when parents did ask about this, there was an apparent lack of discussion or advice from social workers as to who may or may not be appropriate to attend; 'I had no-one to bring with me and I didn't know who to bring with me anyway'.

A finding in other studies that look at parental experiences of CPCs is that parents rarely have sight of professional reports beforehand and the majority of the parents in this study had a similar experience- they report not seeing the written social work report in the days leading up to the CPC, or only getting access to the written report the morning of the conference (Guinan,2004). The implication of not seeing the social worker's report in advance is that parents report that they feel they are on the back foot rather than being well prepared to listen and process information, assessments and reported concerns. It is also clear from parents' responses that 
those parents who did see the social work and other reports prior to the $\mathrm{CPC}$ report felt better prepared and were more likely to engage in the CPC process.

\section{During the Child Protection Conference}

This study also focused on parental experiences of participation during the CPC and how they perceived their contribution to the decision-making processes. Most parents in the study recognised that they had the right to reply to concerns put forward and felt for the most part that they were supported to do so. Yet very few parents reported dissenting or disagreeing during the decision making process and the silencing of some parents also emerges as a finding; '.like, we had to try and take in what he was saying. I had to let some of it go over my head, the thing at the back of my mind was 'just shut up and let them talk and then they won't take the kids'. In this regard, parents preferred to be perceived as cooperative (Slettebø, 2013).

All the parents described how they listened attentively to what was being said. Some parents felt that listening was their only active contribution to the CPC. This is a finding noted in other studies (Corby et al., 1996) where the power asymmetry in the conference can have the effect of silencing parents: 'We were listening more than contributing if that makes sense'.

However, the majority of parents in the study reported that they acted in a manner that suggested compliance or agreement with the child protection plan as it was being discussed and decisions were being made. As one parent recalled: 'We went along with what they said so I suppose they must have thought we were agreeable. I don't think I disagreed as such, but I can't swear that I was actually voluntarily agreeing. It felt more like being backed into a corner.... the stakes are so high it's hard not to be agreeable if they're offering you a way out of losing your children'.

The small number of parents who reported dissenting or disagreeing during the decision-making process generally felt that they were listened to and their views were respected; 'I did object though, they were more or less putting it down on paper as agreed but I said 'No' and that was the end of it'.

As is to be expected in a system where parents are usually involuntary participants, there were frequent references to power and a shared perception of a power imbalance in most of the parents' testimonies; 'It's a power thing, no matter what I said, she (the social worker) was going to be believed'. The theme of a power imbalance and the perception by parents that the child protection conference system is authoritarian is a frequent finding in the literature (Parton 2014; Featherstone et al. 2014). Smithson and Gibson (2016) found that the presence of a power imbalance combined with parents' lack of influence, and the fear their children may be removed minimized opportunities for dissent and had the effect of silencing some parents. 
For social workers and CPC chairpersons, a key message from the study is that the use of professional power and authority can be experienced as belittling by parents, and they may feel this marginalises them during the CPC; 'To be made to feel that you can't look after your own kids... it made me feel small, it did. It made me feel really small, like. I felt very belittled'. However, the perception of a power differential did not necessarily silence all parents in the study. This suggests that the impact of the power imbalance or power asymmetry can be minimized if parents feel a sense of respect and a non-judgmental attitude from the CPC chairperson. This and other studies have found that parental participation is possible at all levels of the CPC, and that parents feel validated once their opinions are sought (Darlington et al. 2012), whether or not those opinions are then acted upon.

\section{After the conference}

The period immediately after the $\mathrm{CPC}$ is a sensitive time when parents are trying to absorb the information they have been given during the CPC. Parents in this study reported that they were not routinely debriefed after the CPC and most reported feeling confused and unclear as to the outcome of the conference:

'There was no talk afterwards.... The social worker that knows that family should sit them down and say 'this is what happened here, this is how I see it, this is it'. That should be done. Instead we just came home and had a cup of tea and just tried to put back the pieces'.

There appears to be less social work activity in this period according to some parents' accounts; a finding that coincides with other studies which suggests that the level of social work support between CPCs is lower than before the initial CPC (Guinan 2004). Given that the majority of parents report feeling unprepared prior to, during and after the conference, there may be diminished returns from parental activity post conference, without adequate social work support. The momentum for achieving improved child protection outcomes is dependent to a great extent on the parent's capacity and motivation to work through the actions in the plan, yet some parents reported feeling that they needed more practical help than they were given during this period to make progress with the plan.

\section{Relationships}

Relationship-based practice is well recognised in the literature as having a pivotal impact on levels of professional engagement and the effectiveness of subsequent interventions (Ruch, 2005). The literature is clear that developing effective 
relationships involves complex processes that operate at a number of different levels (Ruch, 2005; Howe, 1998). In this study, many of the parents spoke favourably about interactions with social workers, social care workers and CPC chairpersons:

She had a lovely way of getting to know us, we felt we could really speak to her, it's a hard thing to do. They need to be able to communicate without taking your selfrespect away. She was able to do that.

They were also able to articulate what they valued about these relationships during the time of the CPC and review process, and to express what they perceived as barriers and challenges to the formation of relationships. Three themes emerge from parents' perspectives; support and help; trust and respect; and the ability to listen: 'I did feel listened to, the support I got from the social worker; that gave me more confidence to speak'. It is clear that when parents were reflecting on what worked well during the $\mathrm{CPC}$ they identified that having a respectful and supportive relationship with the social worker goes some way to minimizing the less positive aspects of the CPC. Lundy's model of participation (2007) identifies the concept of 'space' as providing safe, inclusive opportunities for views to be expressed, and 'voice' as the need for facilitation to express views. While the model is intended to conceptualise children's participation, there may be additionality in its application to supporting participation among other groups.

\section{Impacts and outcomes}

Parents were asked to reflect on the positive and negative impacts and outcomes on their family life as a direct result of the CPC process and the child protection plan which was decided during that process. In contrast with other studies, and despite feeling unprepared and finding the process difficult and stressful to endure, most parents in this study were able to identify a number of positive impacts, outcomes and improvements that the CPC and plan has had on their lives: 'In the end.... it made an awful difference. It was the worst thing that ever happened and the best thing that ever happened' (within an Irish context, 'awful' is often taken to mean 'significant' or 'momentous', rather than having any negative connotations).

Ten parents in the sample population identified a number of positive impacts on their family life as a result of the child protection plan which was formulated at the CPC; parenting had improved; they had better access to appropriate support services; they had more awareness of and control over their personal circumstances; the experience had brought them closer together as a family and their children had benefited from the plan. This is an area that would benefit from more research to determine which specific areas have seen improved outcomes and to identify what aspects of the conference process act as enablers or facilitators for these perceived 
improvements.

Negative impacts and outcomes which were identified by four parents tended to be linked more to their experiences of the CPC process itself rather than the child protection plan. These were reported as the stress of the CPC system on physical and emotional well-being; the worry and fear of being in the system; the perception of being subject to an unfair, unneeded and/ or undeserved process; the feeling of being subjected to ongoing scrutiny and the 'gaze' of other parties that did not diminish after the CPC process concluded, and the impact of feeling labelled a bad parent.

It appears from these responses that the majority of parents in this study were able to pinpoint positive impacts as a direct result of engaging in the CPC system and the child protection plan, despite finding it a disempowering, fearful and stressful process. While most of the research supports the importance of positive experiences for parents in effecting change (Fauth et al., 2010, Smithson \& Gibson 2016), this study indicates that despite finding the process to be generally a negative one, parents still reported positive change.

\section{Recommendations for practice}

A key output of the study was the identification of recommendations for best practice related to CPC delivery. The following are key recommendations arising from the findings of the study:

- It was found that a protocol for parental preparation should be developed and activated prior to parental attendance at a CPC.

- Preparation for a CPC should include acknowledgment of the emotional impact of the CPC on parents.

- Discussions between the social worker and parents regarding advocates and supportive persons should take place prior to a CPC.

- Particular support needs should be addressed if the CPC process has acutely affected parents, before, during and after the CPC.

- It is also recommended that parents are supported to speak up at the CPC or that arrangements are put in place to allow their voice to be heard if they prefer not to speak directly to the CPC.

- Parents who offer alternative suggestions or who disagree with decisions should have their contribution acknowledged and reasons as to why their suggestions are accepted or not should be given.

- Debriefing should become a structured phase of the CPC where parents meet with the chairperson and/ or social worker (as appropriate) to work through the matters that have arisen during the CPC and to ensure that parents are clear 
on decisions that have been made, and what is expected of them.

- Social work input should remain intensive in the days and weeks after the CPC to ensure there are no barriers in place for parents that may prevent them engaging fully with the child protection plan.

\section{Concluding remarks}

Partnership between service providers and families is the act of those parties working together for the benefit of children. Participation is key to achieving and maintaining that partnership (O'Brien and Ahonen, 2015). Parental participation represents a shift from viewing parents as passive beneficiaries of service input to an emphasis on the capacity of service users to be creative, reflective and active agents in shaping their lives (Slettebø, 2013). Translating this message into practice is complex given the range of factors contributing to the power asymmetry in the child protection space. As this is an under-researched topic with a limited evidence base from past studies, the primary data collected for this study in the Irish context provides additional welcome insight into this phenomenon. Findings highlight how parents enter the CPC process with fear and perceived confusion, often wanting to appear cooperative. Feeling powerless throughout the process impacts negatively on their ability to engage with the child protection plans that are decided at the CPCs, while also impacting parents' perceptions of outcomes. This paper illustrates the importance of supporting meaningful participation with parents, ultimately providing recommendations for best practice.

\section{References}

Aarthun, A. and Akerjordet, K. (2014) Parent participation in decision-making in healthcare services for children: an integrative review. Journal of Nursing Management. 22, 2 , 177-191

Arnstein, S. R. (1969) 'A ladder of citizen participation'. Journal of the American Institute of Planners. 35, 4, 216-224

Ayón, C., Aisenberg, E. and Erera, P. (2010) Learning how to dance with the public child welfare system: Mexican parents' efforts to exercise their voice. Journal of Public Child Welfare. 4, 3, 263-286

Brady, B. (2006) Facilitating family decision making: A study of the family. Journal of Criminology, 44, 225-240

Children Act 1989. London: The Stationery Office

Child and Family Agency (2011) Child Protection and Welfare Practice Handbook. Dublin: 
Child and Family Agency

Children and Family Agency (2015) Child Protection Conference and the Child Protection Notification System: Information for professionals. Dublin: Child and Family Agency

Child and Family Agency (2016) Tusla Child and Youth Participation Toolkit. Dublin: Child and Family Agency

Child and Family Agency Act 2013. Dublin: Government Publications

Corby, B., Millar, M. and Young, L. (1996) Parental participation in child protection work: Rethinking the rhetoric. British Journal of Social Work, 26, 4, 475-492

Darlington, Y., Healy, K. and Feeney, J. A. (2010) Challenges in implementing participatory practice in child protection: A contingency approach. Children and Youth Services Review, 32, 7, 1020-1027

Darlington, Y., Healy, K., Yellowlees, J. and Bosly, F. (2012) Parents' perceptions of their participation in mandated family group meetings. Children and Youth Services Review, 34, 2, 331-337

Department of Children and Youth Affairs (2001) The Children Act 2001. Dublin: Stationary Office

Department of Children and Youth Affairs (2011) Children First: National guidance for the protection and welfare of children. Dublin: Government Publications

Department of Children and Youth Affairs (2015) High-Level Policy Statement of Supporting Parents and Families ('Parenting and Family Support'). Dublin: Government Publications

Department of Health (1993) Kilkenny Incest Investigation: Report. Dublin

Department of Health (1995) Notification of Suspected Cases of Child Abuse between Health Boards and Gardaí. Dublin: Department of Health

Department of Health and Children (2008) Service users' perceptions of the Irish child protection system, Dublin: Department of Health and Children

Farmer, E. and Owen, M. (1995) Child Protection Practice: Private risks and public remedies. London: HMSO

Fauth, R., Jelicic, H., Hart, D., Burton S., and Shemmings, D., with Bergeron, C., White, K., and Morris, M., (2010) Effective Practice to Protect Children Living in 'Highly Resistant' Families. London: Centre for Excellence and Outcomes in Children and Young People's Services

Featherstone, B., Morris, K. and White, S. (2014) Re-imagining Child Protection: Towards humane social work with families. Bristol: Policy Press

Gillen, A. (2013) Parenting Support Strategy. Dublin: Child and Family Agency

Guinan, B. (2004) Child Protection Conferences: The parents' perspective a thesis submitted in partial fulfilment of the requirements for the MSc in child protection and welfare [unpublished]. Trinity College Dublin (TCD). Available from: http://www.lenus.ie/hse/ handle/10147/84244 [accessed 3 April 2017]

Hardy, F. and Darlington, Y. (2008) What parents value from formal support services in the context of identified child abuse. Child E Family Social Work. 13, 3, 252-261

Healy, K., Darlington, Y. and Feeney, J. A. (2011) Parents' participation in child protection practice: Toward respect and inclusion. Families in Society. 92, 3, 282-288 
Healy, K., Darlington, Y. and Yellowlees, J. (2012) Family participation in child protection practice: An observational study of family group meetings. Child and Family Social Work. $17,1,1-12$

Höjer, I. (2011) Parents with children in foster Care:How do they perceive their contact with social workers. Practice. 23, 2, 111-123

Horwath, J. and Tarr, S. (2014). Child visibility in cases of chronic neglect: Implications for social work practice. British Journal of Social Work. 45, 1, 1379-1394

Howe, D. (1998). Relationship-based thinking and practice in social work. Journal of Social Work Practice, 12, 1, 45-56

Katz, I., La Placa, V. and Hunter, S. (2007) Barriers to Inclusion and Successful Engagement of Parents in Mainstream Services. York: Joseph Rowntree Foundation

Kilkelly, U. (2004) Children's rights: A European perspective. Judicial Studies Institute Journal. 4, 2, 68-95

Law Reform Commission (1990) Report on Child Sexual Abuse. Dublin: The Law Reform Commission

Lundy, L. (2007) 'Voice is not enough': Conceptualizing Article 12 of the UNCRC. British Educational Research Journal, 33, 6, 927-42

Lupton, C. (1998) User empowerment or family self-reliance? The family group conference model. British Journal of Social Work. 28, 1, 107-128

Mannion, G. (2009). After participation: The socio-spatial performance of intergenerational becoming. in A Handbook of Children and Young People's Participation (pp. 352-364). Routledge

O'Brien, V. and Ahonen, H. (2015) Pathways and Outcomes: A study of 335 Referrals to the Family Welfare Conference (FWC) Service in Dublin, 2011-2013, Dublin: Child and Family Agency

Parton, N. (2014) Social work, child protection and politics: Some critical and constructive reflections. The British Journal of Social Work, 44, 7, 2042-2056

Roose, R., Roets, G., Van Houte, S., Vandenhole, W. and Reynaert, D. (2013) From parental engagement to the engagement of social work services: Discussing reductionist and democratic forms of partnership with families, Child and Family Social Work, 18, 4, 449457

Ruch, G. (2005). Relationship-based practice and reflective practice: holistic approaches to contemporary child care social work. Child \& Family Social Work, 10, 2, 111-123

Smithson, R. and Gibson, M. (2016). Less than human: A qualitative study into the experience of parents involved in the child protection system. Child \& Family Social Work. 22, 2, 565-574

Slettebø, T. (2013) Partnership with parents of children in care: A study of collective user participation in child protection services. British Journal of Social Work. 43, 3, 579-595

United Nations (1989) Convention on the Rights of the Child 